\title{
Metal grids with high-porous surface as structured catalysts: preparation, characterization and activity in propane total oxidation
}

\author{
I. Yuranov, N. Dunand, L. Kiwi-Minsker*, A. Renken \\ Institute of Chemical Engineering, Swiss Federal Institute of Technology, CH-1015 Lausanne, Switzerland
}

Received 15 July 2001; received in revised form 3 September 2001; accepted 13 October 2001

\begin{abstract}
Metal nickel and copper grids are shown to be suitable supports for structured combustion catalysts. The increase of specific surface area (SSA) of metal grids was achieved due to the porous outer layer with the structure of Raney metal developed on the wire surface. Transition metals $(\mathrm{Co}, \mathrm{Cu}, \mathrm{Mn}, \mathrm{Cr})$ oxides were deposited as active components on the pre-oxidized support and tested in total propane oxidation. Cobalt oxide demonstrated the highest activity. Reductive pre-treatment in the flow of hydrogen resulted in a more active catalyst than the activation in oxygen atmosphere. This effect was assigned to the partial reduction of $\mathrm{Co}_{3} \mathrm{O}_{4}$ until metallic $\mathrm{Co}$, which was detected by XPS on the catalyst surface. Deactivation of the pre-reduced Co-oxide catalyst was observed during propane combustion in excess of oxygen and was ascribed to the oxidation of partially reduced active phase. After $4 \mathrm{~h}$ on stream, the catalyst reached his steady-state and showed stable activity without further deactivation. The catalytic activity expressed in the terms of propane conversion was observed to depend on the propane/oxygen ratio. () 2002 Elsevier Science B.V. All rights reserved.
\end{abstract}

Keywords: Catalytic combustion; Total propane oxidation; Metal oxide catalysts; Metal grids; Structured catalytic bed; Raney metals

\section{Introduction}

Catalytic combustion is widely used to remove pollutants from exhaust gases, and has gained considerable attention during the last decades [1,2]. The main advantage of catalytic combustion is the low operating temperature, decreasing the formation of toxic nitrogen oxides. Incinerators based on catalytic combustion typically operate at temperatures below $673 \mathrm{~K}$ and at GHSV from 1000 to $100,000 \mathrm{~h}^{-1}$. Highly active catalysts ensuring complete oxidation within short residence times are required.

\footnotetext{
* Corresponding author. Tel.: +41-21-693-31-82; fax: +41-21-693-31-90.

E-mail address: lioubov.kiwi-minsker@epfl.ch (L. Kiwi-Minsker).
}

Another important point concerns the catalyst packing. Incinerators with randomly packed catalytic beds may suffer of a high pressure drop, gas channeling and fouling by dust. Therefore, structured catalytic beds of ceramic and metal monoliths have been developed for catalytic combustion reactors [2]. The main drawbacks of ceramic monoliths are: high weight to volume ratio, high manufacturing cost and their susceptibility to thermal/mechanical shock. Structured catalytic beds made from metal wire grids have an open regular structure, which provides a low pressure drop during the passage of gases through the catalytic bed and a good resistance to mechanical stress. Metallic wire-based catalysts due to high thermal conductivity are stable to thermal shock and also show diminished hot spots formation in exothermic reactions. 
Only scant information about wire-based catalysts is available in the literature. Different metal wires $(\mathrm{Ni} / \mathrm{Cr}, \mathrm{Cu})$ were used as catalysts in hydrocarbon combustion after oxidative pre-treatment in oxygen $[3,4]$. The problem of using metal grids as catalysts, is related to their low specific surface area (SSA). A deposition of an homogeneous wash-coat oxide layer on a metal wire surface still remains difficult [5].

Therefore, the search of novel catalytic materials for structured combustion reactors is warranted. In this study, the catalysts based on modified metal grids are proposed for total oxidation of hydrocarbons. In order to increase a SSA of metal wires, first a thin Raney-type outer layer was formed on the metal surface. Oxidation of this layer resulted in a highly porous oxide strongly attached to the metal surface, which allowed a deposition of a catalytically active component. The p-type oxides of different transition metals $(\mathrm{Cr}, \mathrm{Mn}, \mathrm{Cu}, \mathrm{Co}, \mathrm{Ni}$,) were tested during total propane oxidation. Metal oxides are generally less active compared to noble metal catalysts, but they are known to have better resistance to certain poisons, especially halogens, $\mathrm{As}, \mathrm{Pb}$ and $\mathrm{P}$.

\section{Experimental}

\subsection{Catalyst preparation}

Commercially available metal grids (made of nickel or copper) were used as starting materials. The procedure of the support preparation is schematically presented in Fig. 1. The grids are knitted from the wires with a diameter of $100 \mu \mathrm{m}$. They have a specific surface area of about $10^{-3} \mathrm{~m}^{2} / \mathrm{g}$, which corresponds to the geometrical surface. In order to increase the SSA of the material, a thin Raney-type porous layer was created on the wire surface. First, Al alloy on the Ni (or $\mathrm{Cu}$ ) wire was formed via solid-solid reaction with aluminum powder [6]. Aluminum was leached out in an acidic $(10 \mathrm{wt} . \% \mathrm{HCl})$ or alkaline $(10 \mathrm{wt} . \% \mathrm{KOH})$ aqueous solution at $363 \mathrm{~K}$ yielding a skeletal metal layer. Porous outer layer significantly increased the SSA of the grids up to $20 \mathrm{~m}^{2} / \mathrm{g}$. The nickel grid with skeletal outer layer was observed to be highly pyrophoric, oxidizing spontaneously and generating a large amount of heat in dry air at room temperature. For this reason, the skeletal nickel grid was stored under water to avoid an oxidation of its surface. Copper grids with a Raney outer layer were observed to be stable in dry air at room temperature and were oxidized at $773 \mathrm{~K}$ in air.

In some cases, layer of copper oxide was deposited on the modified surface of nickel grid by treating a freshly prepared skeletal Ni grid in an aqueous ammonia solution of $\mathrm{Cu}$ (II) acetate for $30 \mathrm{~min}$. The nickel surface was covered by metallic copper according to the reaction: $\mathrm{Ni}+\mathrm{Cu}^{2+} \rightarrow \mathrm{Ni}^{2+}+\mathrm{Cu}$. The color of the nickel grid was observed to change from black to red, indicating a deposition of metallic copper and then turned black again. Finally, the grids were calcined in air at $773 \mathrm{~K}$ to form nickel and copper oxides on the surface and the materials were used as the supports for catalyst preparations. So, the obtained support materials consisted of a metallic core $(\mathrm{Ni}$ or $\mathrm{Cu})$ with an oxide ( $\mathrm{NiO}$ or $\mathrm{CuO})$ as an outer layer.

Oxides of metals like $\mathrm{Co}, \mathrm{Cu}, \mathrm{Mn}, \mathrm{Cr}$ are known to be active in catalytic combustion of VOCs $[7,16,17]$. They were deposited on the metal grid supports by wet impregnation from aqueous solutions (10-20 wt.\%) of cobalt, copper, and manganese acetates. Ammonium dichromate was used as a precursor for chromium

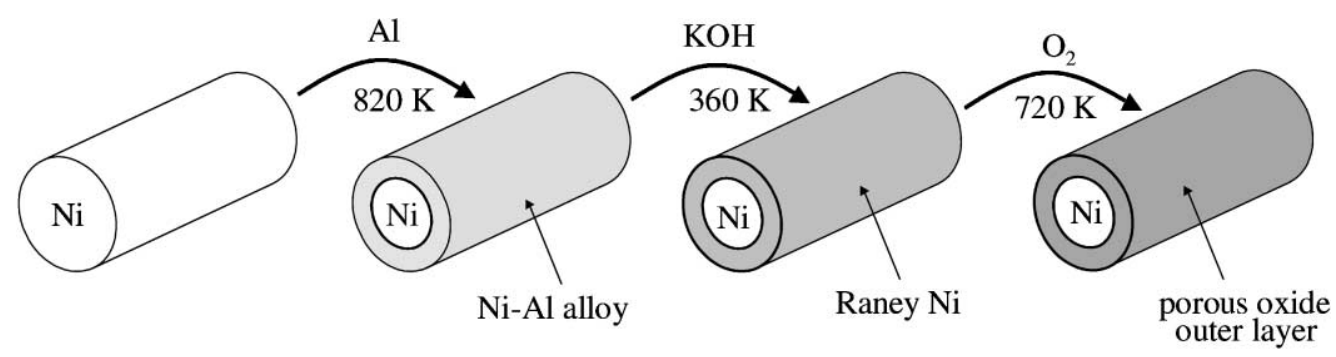

Fig. 1. Schematic presentation of the preparation procedure of porous oxide layer on metal grid via formation of outer layer with Raney-type structure. 
Table 1

The main characteristics of the catalysts tested during propane total oxidation

\begin{tabular}{llrr}
\hline Catalyst & SSA $\left(\mathrm{m}^{2} / \mathrm{g}\right)$ & Pore volume $\left(\mathrm{cm}^{3} / \mathrm{g}\right)$ & $T_{50 \%}(\mathrm{~K})$ \\
\hline $\mathrm{CuO} / \mathrm{Cu}$ & 16.5 & $3.1 \times 10^{-2}$ & $>800$ \\
$1 \mathrm{Co}_{3} \mathrm{O}_{4} / \mathrm{CuO} / \mathrm{Cu}$ & & & $>800$ \\
$\mathrm{NiO} / \mathrm{Ni}$ & 14.0 & $2.8 \times 10^{-2}$ & $>800$ \\
$\mathrm{CuO} / \mathrm{Ni}$ & 15.2 & $3.0 \times 10^{-2}$ & $>800$ \\
$1 \mathrm{Co}_{3} \mathrm{O}_{4} / \mathrm{NiO} / \mathrm{Ni}$ & & & $\sim 775$ \\
$1 \mathrm{Co}_{3} \mathrm{O}_{4} / \mathrm{CuO} / \mathrm{Ni}$ & 19.0 & $5.4 \times 10^{-2}$ & 653 \\
$1\left(2 \mathrm{Co}_{3} \mathrm{O}_{4}+\mathrm{CuO}\right) / \mathrm{CuO} / \mathrm{Ni}$ & & & 683 \\
$1.5\left(2 \mathrm{Mn}_{3} \mathrm{O}_{4}+\mathrm{CuO}\right) / \mathrm{CuO} / \mathrm{Ni}$ & & & 690 \\
$1\left(\mathrm{Co}_{3} \mathrm{O}_{4}+\mathrm{CuO}\right) / \mathrm{NiO} / \mathrm{Ni}$ & & & $>800$ \\
$1\left(\mathrm{Co}_{3} \mathrm{O}_{4}+\mathrm{CuO}\right) / \mathrm{CuO} / \mathrm{Ni}$ & & & 702 \\
$0.9 \mathrm{Mn}_{3} \mathrm{O}_{4} / \mathrm{NiO} / \mathrm{Ni}$ & & & $>800$ \\
$1 \mathrm{Mn}_{3} \mathrm{O}_{4} / \mathrm{CuO} / \mathrm{Ni}$ & & & 709 \\
$0.9 \mathrm{Cr}_{2} \mathrm{O}_{3} / \mathrm{CuO} / \mathrm{Ni}$ & & & $>800$ \\
$0.9 \mathrm{Cr}_{2} \mathrm{O}_{3} / \mathrm{CuO} / \mathrm{Ni}$ & & $>800$ \\
\hline
\end{tabular}

oxide deposition. After impregnation the grids were dried at $373 \mathrm{~K}$ and calcined in air at $923 \mathrm{~K}$ for $30 \mathrm{~min}$. The impregnation was repeated several times to reach the desired loading of the active phase and then calcinations was carried out during $12 \mathrm{~h}$ at $923 \mathrm{~K}$ in air.

The catalysts studied and their main characteristics are listed in Table 1. The metallic supports with the porous oxide outer layer are denoted as $\mathrm{NiO} / \mathrm{Ni}$, $\mathrm{CuO} / \mathrm{Cu}$ and $\mathrm{CuO} / \mathrm{Ni}$. The amount of the active phase deposited on the support is presented in weight percentages. For example, $1\left(\mathrm{Co}_{3} \mathrm{O}_{4}+\mathrm{CuO}\right) / \mathrm{CuO} / \mathrm{Ni}$ corresponds to $1 \mathrm{wt} . \%$ of mixed oxide $\mathrm{Co}_{3} \mathrm{O}_{4}: \mathrm{CuO}=$ $1: 1$, deposited on nickel wire with the porous outer layer consisting of copper oxide.

\subsection{Catalyst characterization}

The surface morphology of the synthesized supports and of the catalysts was investigated via scanning electronic microscopy (JSM 6300F, JEOL). X-ray photoelectron spectroscopy (XPS) (PHI-550, ESCA-System spectrometer, Perkin-Elmer) in combination with ion sputtering $\left(\mathrm{Ar}^{+}\right.$ions at $3.5 \mathrm{keV}$, sputter rate of $50 \mathrm{~nm} / \mathrm{min}$ ) was used to determine the chemical composition of the catalyst outer layer. The BET surface area and pore size distribution of the catalysts were measured by nitrogen adsorption-desorption isotherms at $77 \mathrm{~K}$ via a Sorptomatic 1900 (Carlo Erba) instrument.

\subsection{Experimental set-up}

The propane oxidation was carried out in a continuous flow fixed-bed reactor [8] operated as a plug flow reactor. Wire grid catalyst $(\sim 0.4 \mathrm{~g})$ was rolled-up (packing density, PD $\sim 400 \mathrm{~kg} / \mathrm{m}^{3}$ ) or cut into small pieces $\left(\mathrm{PD} \sim 2000 \mathrm{~kg} / \mathrm{m}^{3}\right.$ ) and placed into the middle section of the reactor. To avoid a flow maldistribution, quartz beads were placed after the grid catalyst in the catalytic bed. During the catalyst testing no influence of packing density on catalytic behavior was observed. The cut catalysts with PD $\sim 2000 \mathrm{~kg} / \mathrm{m}^{3}$ and the total gas flow of $100 \mathrm{ml} / \mathrm{min}$ (STP) were used throughout the study. The propane (10 vol.\% in argon), oxygen and argon (provided by Carbagas, Lausanne, Switzerland, >99.99\%) were used as received without any purification. The gas flows were controlled by mass flow controllers. The temperature in the catalytic bed was monitored by a thermocouple. The outlet carbon monoxide and carbon dioxide gas concentrations were monitored continuously by an infrared analyzer Ultramat 22P (Siemens). Propane concentration was measured chromatographically by GC 8000 (Fisons Instruments, Carboxen 1000 column, $598 \mathrm{~K}, 50 \mathrm{ml} / \mathrm{min}$ of He carrier gas).

A gas mixture of $0.5 \mathrm{vol} . \%$ propane and $10 \mathrm{vol} . \%$ oxygen in argon was used for the catalyst screening. Before the reaction, the catalysts were pre-treated in $10 \mathrm{vol} . \%$ oxygen in argon at $573 \mathrm{~K}$ during $30 \mathrm{~min}$. The reaction temperature was increased (heating rate of 
$5 \mathrm{~K} / \mathrm{min}$ ) stepwise by $20 \mathrm{~K}$ from 298 to $723 \mathrm{~K}$. The conversion values are reported after a steady-state was attained at each temperature (after 1-1.5 h). The catalytic activity is characterized by the temperature necessary to attain a $50 \%$ propane conversion.

Reductive pre-treatment/activation of the cobalt oxide catalyst was carried out in the stream of hydrogen at $673 \mathrm{~K}$ during $1 \mathrm{~h}$. In order to investigate influence of the propane to oxygen ratio on the catalytic activity of the pre-reduced cobalt oxide catalysts, the gas mixture containing 0.5 vol. $\%$ propane and 2.5 vol. $\%$ oxygen (stoichiometric ratio) in argon was used as reference along with the standard mixture.

\section{Results and discussion}

\subsection{Catalysts}

Characteristic parameters of the supports and catalysts are summarized in Table 1. The SSA increases due to the formation of the skeletal (Raney-type) porous outer layer on the wire surface. The SEM images of the supports and their surface morphology are shown on Fig. 2 for Ni-grid and on Fig. 3 for Cu-grid. The wires are shown to be completely covered by the oxide layer with highly developed porous structure. The fine structure of the Ni-outer layer consists of

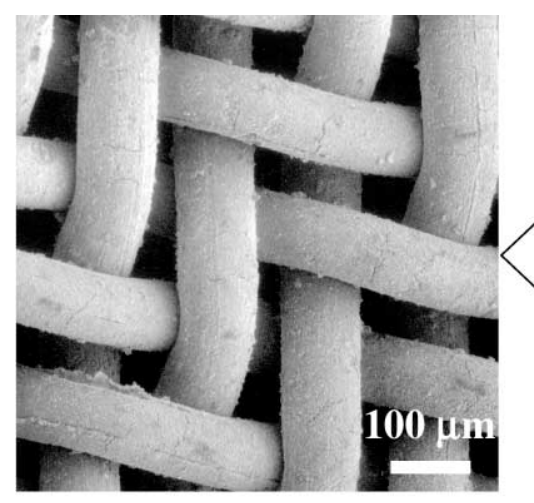

(a)

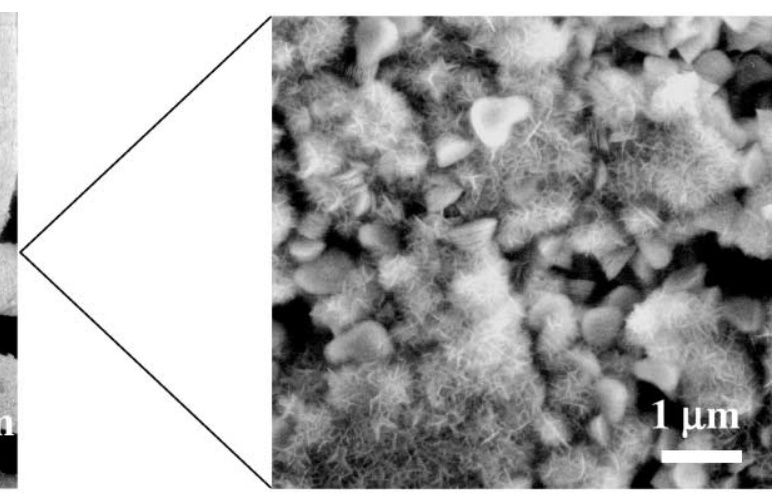

(b)

Fig. 2. (a and b) SEM image of Ni-grid support with Raney-type outer layer at different magnifications.

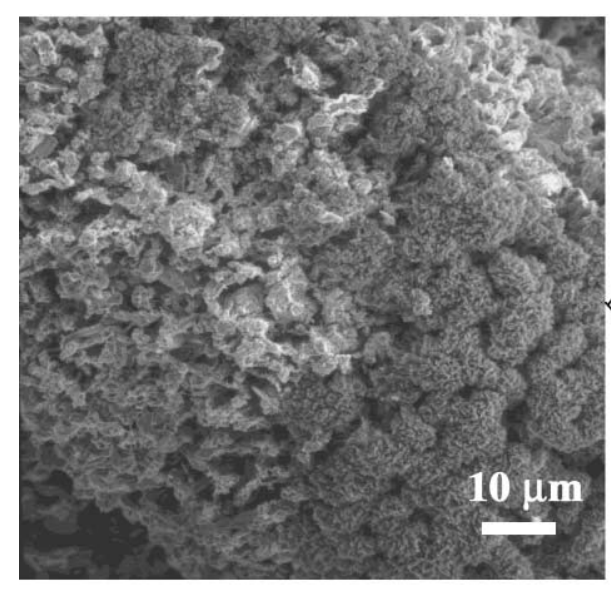

(a)

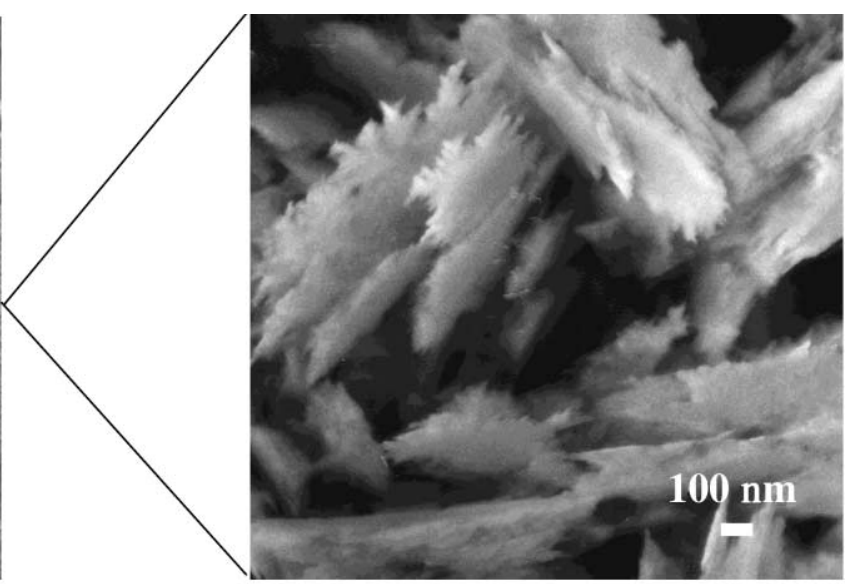

(b)

Fig. 3. ( $a$ and b) SEM image of Cu-grid support with Raney-type outer layer at different magnifications. 


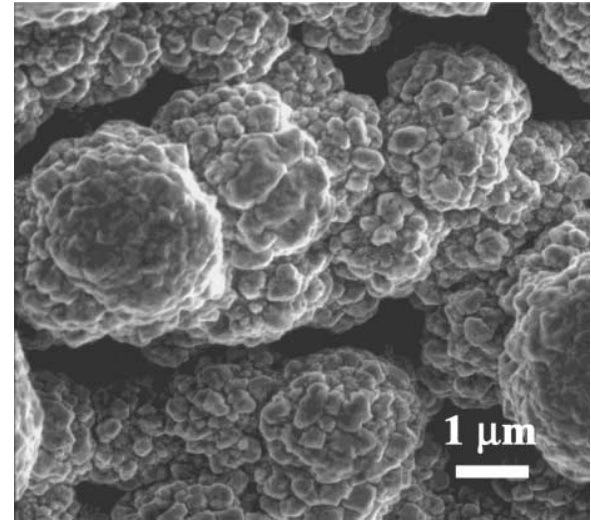

Fig. 4. SEM image of the surface of skeletal nickel covered by metallic copper.

sub-micron size oval blocks with needle-shape particles of nickel oxide on the outer surface (see Fig. 2b). The copper wire with the Raney-type outer layer (Fig. 3a and b) was stable in air at room temperature. This was also the case for skeletal nickel covered by metallic copper, with surface morphology presented on Fig. 4. The oxidation of the Raney-type layers of copper wire was performed at $773 \mathrm{~K}$ in air, resulting in highly porous oxide layer.

Fig. 5 shows the surface morphology of final catalyst obtained after an active component (cobalt oxide) deposition. Along with fine micro-porous layer, the macro-pores of a few microns diameter (cracks) were always observed on the catalyst surface. These cracks are probably formed during the calcination step due

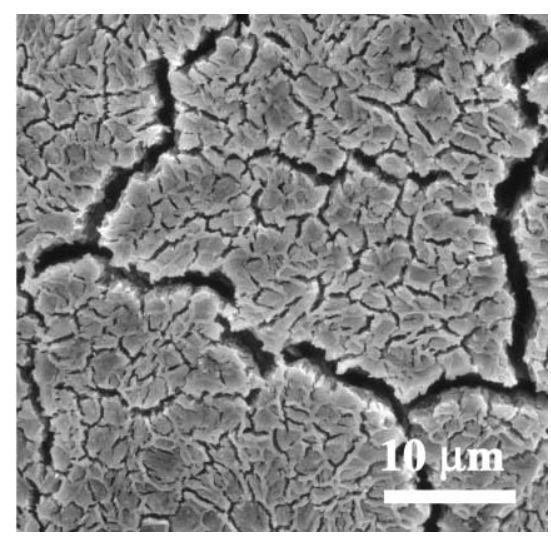

Fig. 5. SEM image of $1 \mathrm{Co}_{3} \mathrm{O}_{4} / \mathrm{CuO} / \mathrm{Ni}$ catalyst surface. to the different dilatation coefficients of metallic wire and surface oxide.

\subsection{Catalyst screening}

The most active single metal oxide catalysts for complete oxidation of a variety of organic compounds are found to be oxides of $\mathrm{Cr}, \mathrm{Mn}, \mathrm{Fe}, \mathrm{Co}, \mathrm{Ni}$, and $\mathrm{Cu}$ [16]. These are p-type semiconductor oxides and are able to adsorb oxygen by donating an electron from the metal cation. This process leads to a formation of electrophilic oxygen species $\left(\mathrm{O}_{2}{ }^{-}, \mathrm{O}^{-}\right)$known to be active in deep oxidation. For this reason, these p-type oxides were used as active components deposited on metal grids supports and tested for the catalytic activity during the total propane oxidation. The results are presented in Table 1 . The propane conversion as a function of the temperature is shown on Fig. 6. Carbon dioxide and water were the only reaction products observed. The temperatures of $50 \%$ conversion of propane were used to compare the activity of the catalysts under the study.

Cobalt oxide was observed to be the most active for total propane oxidation. This agrees with the results reported by different authors [1,2,9-15] for total oxidation of hydrocarbons: $\mathrm{Co}_{3} \mathrm{O}_{4}>\mathrm{Mn}_{3} \mathrm{O}_{4}>$ $\mathrm{Cr}_{2} \mathrm{O}_{3}>\mathrm{CuO}$.

The support composition strongly influences the cobalt oxide activity, which was observed to decrease in the order: $\mathrm{CuO} / \mathrm{Ni}>\mathrm{NiO} / \mathrm{Ni}>\mathrm{CuO} / \mathrm{Cu}$.

The layer of copper oxide deposited directly on the surface of skeletal nickel significantly increases the activity of the transition metal oxides. Mixed oxides have been reported to have a higher activity in combustion reactions compared to the single oxide components [16]. This is supposed to be due to the multiple energy levels of the metals and their associated oxygen anions, making them more mobile on the surface as compared to single oxides.

$\mathrm{Co}_{3} \mathrm{O}_{4}$ supported on $\mathrm{CuO} / \mathrm{Ni}$ grid demonstrated the highest activity compared to the other catalysts. Moreover, catalytic activity was observed to be significantly enhanced by the catalyst pre-treatment in hydrogen at $673 \mathrm{~K}$ during $1 \mathrm{~h}$. The increased catalytic activity of cobalt oxide after pre-reduction in terms of light-off performance and overall conversion has been already reported in the literature [15]. The high activity was suggested to be due to the occurrence of metallic 


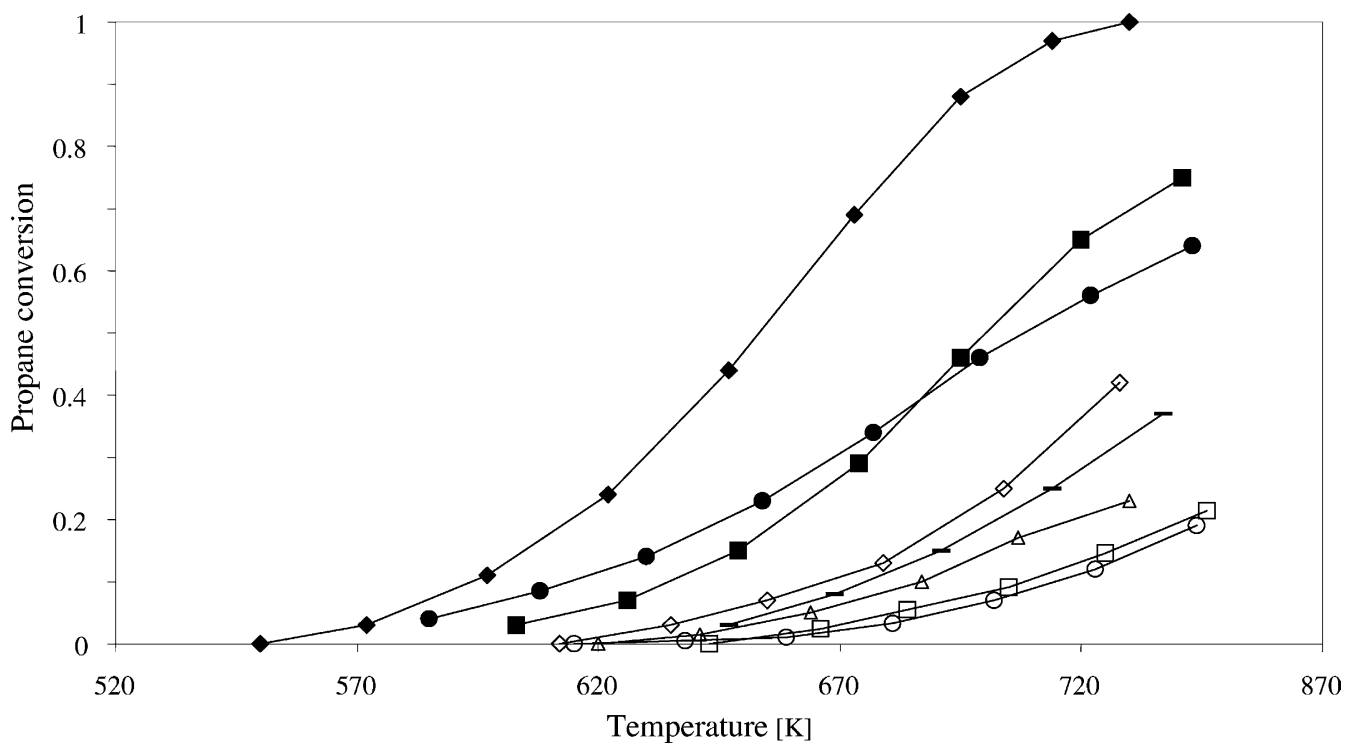

Fig. 6. Temperature dependence of propane conversion over different catalysts: GHSV $=20,000 \mathrm{~h}^{-1}(\mathrm{STP}) ; C_{\mathrm{O}_{2}}=10$ vol. $\%$; $C_{\mathrm{C}_{3} \mathrm{H}_{8}}=0.5$ vol.\%. $1 \mathrm{Co}_{3} \mathrm{O}_{4} / \mathrm{NiO} / \mathrm{Ni}(\diamond) ; 1 \mathrm{Co}_{3} \mathrm{O}_{4} / \mathrm{CuO} / \mathrm{Ni}(\diamond) ; 1\left(\mathrm{Co}_{3} \mathrm{O}_{4}+\mathrm{CuO}\right) / \mathrm{NiO} / \mathrm{Ni}(\square) ; 1\left(\mathrm{Co}_{3} \mathrm{O}_{4}+\mathrm{CuO}\right) / \mathrm{CuO} / \mathrm{Ni}(\square) ; 0.9 \mathrm{Mn} 3 \mathrm{O}_{4} / \mathrm{NiO} / \mathrm{Ni}(\mathrm{O}) ;$ $0.9 \mathrm{Cr}_{2} \mathrm{O}_{3} / \mathrm{CuO} / \mathrm{Ni}(\triangle) ; 1.0 \% \mathrm{Mn}_{3} \mathrm{O}_{4} / \mathrm{CuO} / \mathrm{Ni}(\mathbf{O}) ; \mathrm{CuO} / \mathrm{Cu}(\mathbf{-})$.

cobalt and reduced cobalt-oxide sites on the catalyst surface.

In order to investigate the active phase of the pre-reduced $\mathrm{Co}_{3} \mathrm{O}_{4} / \mathrm{CuO} / \mathrm{Ni}$, the catalyst was examined by XPS in combination with ion sputtering. The results demonstrate that a nickel oxide layer with a thickness of $\sim 500 \mathrm{~nm}$ covered the nickel wire. Metallic cobalt along with cobalt mixed oxides was detected in the outer layer of the pre-reduced catalyst (Fig. 7). Therefore, highly dispersed metallic cobalt is supposed to be responsible for the higher activity of the pre-reduced $\mathrm{Co}_{3} \mathrm{O}_{4} / \mathrm{CuO} / \mathrm{Ni}$ catalysts. Sintering of metallic cobalt particles and their oxidation may cause the catalyst deactivation under the oxidative reaction conditions. The catalyst was observed to loose its initial activity (see Fig. 8) during about $4 \mathrm{~h}$ on stream. After the reaction, only mixed cobalt oxides were detected on the catalyst surface by XPS (Fig. 7).

In fact, the evolution of microstructure and morphology of $\mathrm{Co}_{3} \mathrm{O}_{4}$ catalytic particles was recently studied via high resolution transmission electron microscopy (HRTEM) and selected area electron diffraction (SAED) methods [18]. After the reduction in hydrogen at temperatures as low as $573 \mathrm{~K}$ based on SAED and HRTEM results, the authors suggest the co-existence of $\mathrm{Co}, \mathrm{CoO}$ and $\mathrm{Co}_{3} \mathrm{O}_{4}$ phases and their mutual crystallographic orientation on the catalyst surface.

The Mars-van Krevelen mechanism, which involves reduction-oxidation cycle of the catalyst surface has been assumed for deep oxidation of hydrocarbons over transition metal oxides. The activity of the catalyst for deep oxidation is known to depend on the oxygen mobility, which results from so-called "weak" metal-oxygen bonds. A high number of surface oxygen with low energies of binding to the oxide surface (Me-O bond) have been reported to be required for the catalysts active in deep oxidations [17]. Haber and coworkers $[19,20]$ postulates that electrophilic oxygen species $\left(\mathrm{O}_{2}{ }^{-}, \mathrm{O}^{-}\right)$formed on the surface ensure a highly active non-selective catalytic behavior of the material. A formation of $\mathrm{O}_{2}{ }^{-}, \mathrm{O}^{-}$species on the oxide surface proceeds during the step of surface re-oxidation via diatomic oxygen adsorption and electron transfer:

$$
\begin{aligned}
& \mathrm{O}_{2(\mathrm{~g})}+\mathrm{e}^{-}+[] \rightarrow\left[\mathrm{O}_{2}^{-}\right] \\
& {\left[\mathrm{O}_{2}^{-}\right]+\mathrm{e}^{-}+[] \rightarrow 2\left[\mathrm{O}^{-}\right]} \\
& {\left[\mathrm{O}^{-}\right]+\mathrm{e}^{-} \rightarrow\left[\mathrm{O}^{2-}\right]}
\end{aligned}
$$




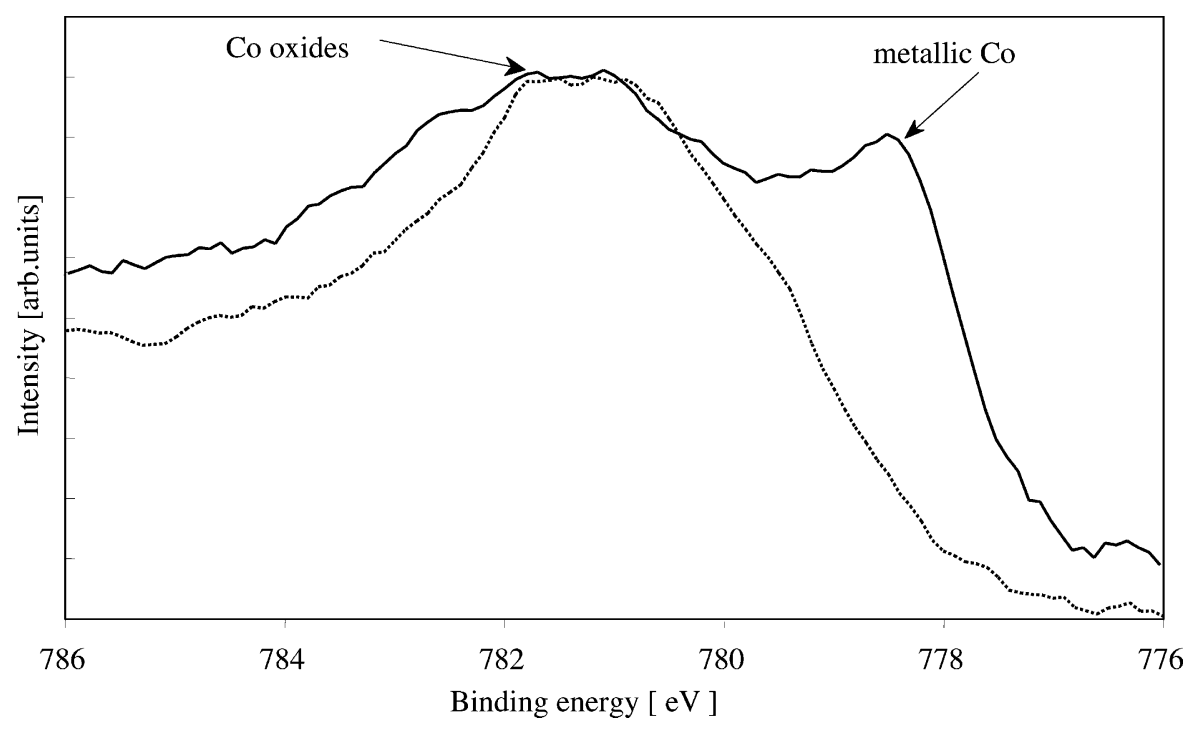

Fig. 7. $\mathrm{Co}_{2 \mathrm{p}}$ XPS spectrum of the pre-reduced $1 \mathrm{Co}_{3} \mathrm{O}_{4} / \mathrm{CuO} / \mathrm{Ni}$ catalyst before and after reaction: $C_{\mathrm{O}_{2}}=10$ vol. $\%, C_{\mathrm{C}_{3} \mathrm{H}_{8}}=0.5 \mathrm{vol} . \%$. Before the reaction (-); after the reaction $(\cdots)$.

The $\left[\mathrm{O}^{2-}\right]$ species is nucleophilic and incorporated into the oxide lattice. The surface concentration of electrophilic oxygen $\left(\mathrm{O}_{2}{ }^{-}, \mathrm{O}^{-}\right)$should depend on the nature and oxidation state of the lattice cations. The presence of reduced cations and the easy electronic transfer are required for increased concentration of the active oxygen species. Therefore, to activate the metal oxide catalyst reductive pre-treatment is necessary.

Moreover, it is well known that the catalysts adapts itself under the reaction conditions. Therefore, the

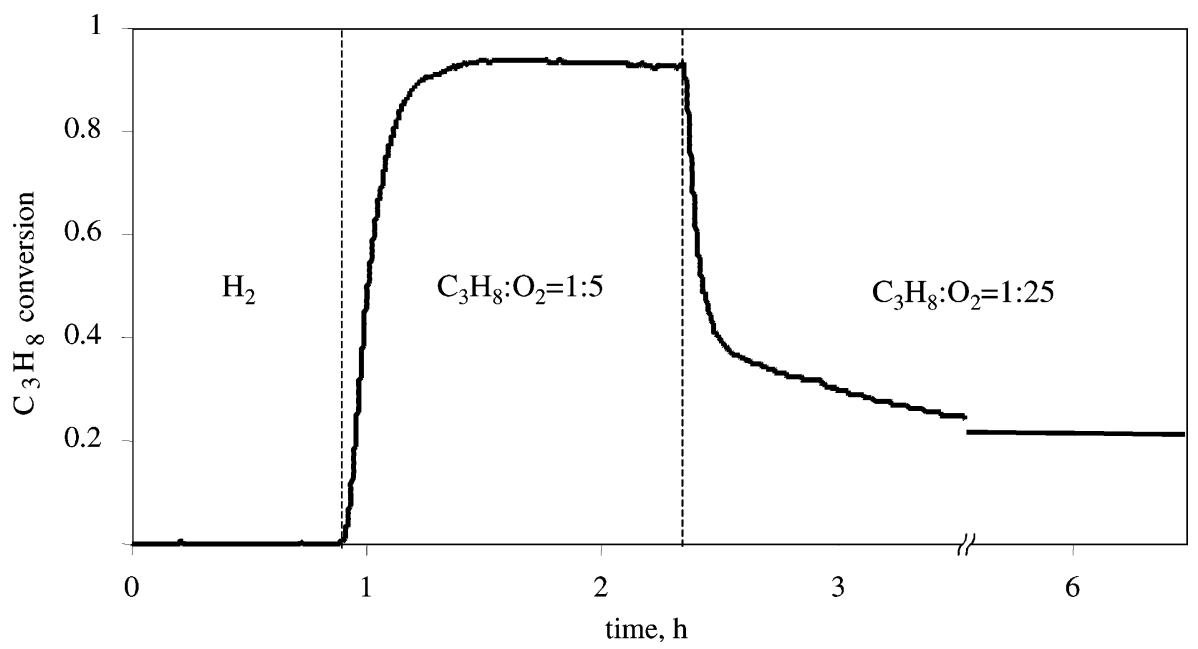

Fig. 8. Dynamics of $1 \mathrm{Co}_{3} \mathrm{O}_{4} / \mathrm{CuO} / \mathrm{Ni}$ catalytic activity during propane total oxidation as a function of oxygen concentration in the reaction mixture: GHSV $=20,000 \mathrm{~h}^{-1}(\mathrm{STP}) ; T=623 \mathrm{~K}$; propane/oxygen ratio is indicated. 
steady-state activity will depend on the reaction media and should be higher at low ratios of propane to oxygen (more reductive conditions), which preserves the catalyst surface from the oxidation. Since the hydrocarbon adsorption (Mars-van Krevelen mechanism) is the rate-determining step during deep hydrocarbon oxidation, facilitating of this step will result in increased catalytic activity.

\subsection{Influence of the propaneloxygen ratio on the steady-state activity}

In order to investigate an influence of the oxygen concentration on the activity/stability of the cobalt oxide supported on $\mathrm{CuO} / \mathrm{Ni}$, propane oxidation was tested over the catalysts activated in hydrogen (at $620 \mathrm{~K}$ during $2 \mathrm{~h}$ ) using the stoichiometric propane/oxygen $(\mathrm{P} / \mathrm{O})=1: 5$ mixture. First, the catalyst was reduced and then, the flow was switched to the stoichiometric $\mathrm{P} / \mathrm{O}$ mixture. After the system reached steady-state (see Fig. 8), the gas flow was switched to a mixture containing a big excess of oxygen $(\mathrm{P} / \mathrm{O}=1: 25$-oxidative conditions). As can be seen from Fig. 8, after reductive pre-treatment the catalyst is highly active and demonstrates stable activity in a stoichiometric reactant mixture. In a mixture containing excess oxygen, a strong deactivation of the catalyst is observed. Deactivation takes place during about $4 \mathrm{~h}$ of time-on-stream, attaining new steady-state. Oxidation of the reduced cobalt species, which stabilize an electrophilic oxygen $\left(\mathrm{O}_{2}^{-}, \mathrm{O}^{-}\right)$active in combustion, may cause the observed deactivation. Reduction of the deactivated (oxidized) catalyst restores its initial catalytic activity.

\section{Conclusions}

- Metal grids with the outer surface layer of Raneytype structure are proposed as suitable supports for the structured catalytic combustion reactors.

- Copper oxide sub-layer obtained via metallic copper deposition on Raney-type surface of nickel grids leads to a significantly increased activity of supported transition metal oxides.

- Cobalt oxide supported on a modified Ni-grid was found as the most active catalyst during propane total oxidation. Reductive pre-treatment by hydrogen increases its catalytic activity. This is ascribed to the highly dispersed particles of metallic Co detected via XPS on the catalyst surface.

- The support composition is seen to influence the cobalt oxide activity. A decrease in the following order: $\mathrm{CuO} / \mathrm{Ni}>\mathrm{NiO} / \mathrm{Ni}>\mathrm{CuO} / \mathrm{Cu}$ is observed.

- Catalyst deactivation was observed during the propane combustion in oxygen-rich atmosphere and is suggested to be due to the oxidation of the reduced cobalt oxide active phase.

\section{Acknowledgements}

The financial support from the Swiss National Science foundation is gratefully acknowledged. We also thank E. Casali, P. Möckli and B. Senior for technical assistance in catalyst characterizations.

\section{References}

[1] M.F.M. Zwinkels, S.G. Järås, P.G. Menon, Catal. Rev.-Sci. Eng. 35 (1993) 319-358.

[2] J.T. Kummer, Prog. Energy Combust. Sci. 6 (1980) 177199.

[3] W. Gürtler, J. Ackermann, G. Emig, Chem. Ing. Technol. 68 (1996) 1438-1442.

[4] W. Gürtler, DE Patent 19611395C1 (1997), Max Rhodius $\mathrm{GmbH}$.

[5] R.E. Hayes, S.T. Kolaczkowski, Introduction to Catalytic Combustion, Gordon and Breach, Amsterdam, 1997, pp. $25-40$.

[6] M.S. Wainwright, Skeletal metal catalysts, in: Handbook of Heterogeneous Catalysis, Vol. 1, Weinheim, VCH, 1997, pp. 64-72.

[7] P. Artizzu, E. Garbowski, M. Primet, Y. Brulle, J. Saint-Just, Catal. Today 47 (1999) 83-93.

[8] L. Kiwi-Minsker, I. Yuranov, E. Slavinskaia, V. Zaikovskii, A. Renken, Catal. Today 59 (2000) 61-68.

[9] A.K. Neyestanaki, L.-E. Lindfors, Combust. Sci. Technol. 110/111 (1995) 303-320.

[10] Y.F. Yu Yao, J. Catal. 33 (1974) 108-122.

[11] J.J. Spivey, J.B. Butt, Catal. Today 11 (1992) 465-500.

[12] Y.F. Yu Yao, J. Catal. 39 (1975) 104-114.

[13] M. O'Connell, A.K. Norman, C.F. Hüttermann, M.A. Morris, Catal. Today 47 (1999) 123-132.

[14] D. Pope, D.S. Walker, R.L. Moss, Atmos. Environ. 10 (1976) 951-956. 
[15] A. Törncrona, M. Skoglundh, P. Thormählen, E. Fridell, E. Jobson, Appl. Catal. B 14 (1997) 131-146.

[16] J.J. Spivey, Ind. Eng. Chem. Res. 26 (1987) 2165-2180, and references cited therein.

[17] V.D. Sokolovskii, Catal. Rev.-Sci. Eng. 32 (1990) 1-49, and references cited therein.
[18] D. Potoczna-Petru, L. Kepinski, Catal. Lett. 73 (1) (2001) 41-46.

[19] A. Bielanski, J. Haber, Oxygen in Catalysis, Dekker, New York, 1991, pp. 392-403.

[20] J. Haber, Stud. Surf. Sci. Catal. 110 (1997) 1. 